International Journal of Dairy Processing \& Research (IJDPR)

\title{
Managing Metabolic Disorders by Timing of Food Observation and Ingestion: Insights from Dairy Science
}

\author{
Akbar Nikkhah
}

Editorial

Foremost Highly Distinguished Professor, Department of Animal Sciences, Faculty of Agricultural Sciences, University of Zanjan, Zanjan, Iran.

\section{*Corresponding Author:}

Akbar Nikkhah,

Foremost Highly Distinguished Professor, Department of Animal Sciences, Faculty of Agricultural Sciences, University of Zanjan, Zanjan, Iran.

Tel: +98-24-33052801

Fax: +98-24-33053202

E-mail: nikkhah@znu.ac.ir, anikkha@yahoo.com

Recieved: October 28, 2014

Published: November 04, 2014

Citation: Akbar Nikkhah (2014) Managing Metabolic Disorders by Timing of Food Observation and Ingestion: Insights from Dairy Science. Int J Dairy Process Res. 1(1e), 1-2.

doi: http://dx.doi.org/10.19070/2379-1578-140001e

Copyright: Akbar Nikkhah ${ }^{\odot}$ 2014. This is an open-access article distributed under the terms of the Creative Commons Attribution License, which permits unrestricted use, distribution and reproduction in any medium, provided the original author and source are credited.

This editorial aims to establish that the emerging science of 'food observation and ingestion timing' requires expanded future attention in optimizing the worldwide public health. Insulin as the main storage hormone stimulates glucose entry into peripheral adipocytes and muscle cells. More glucose enters the portal vein in humans than in dairy herbivores. As a result, insulin has more significant effects on the hepatic glucose uptake and metabolism in humans. Nervous system, gut peptides, pancreatic secretions, and nutrient absorption all induce insulin release. Nervous-wise, insulin is released by the action of sympathetic and parasympathetic neurons. Food vision, odor, and flavor can also induce insulin secretion by activating parasympathetic neurons in humans.

Early fundamental research established that neural impulses and gastrointestinal hormones are involved in ruminant postprandial insulin responses. Secretion and pancreozymin stimulated insulin release in sheep. The blood insulin rise precedes that of glucose, suggesting that glucose is not necessarily a major cause of the initial postprandial rise in insulin release. Based on the most recent discoveries, such effects depend on eating or food ingestion timing. Dairy cows fed once daily at 2100 hours exhibited a prefeeding decline in blood glucose that progressed until $2 \mathrm{~h}$ postfeeding before reaching the baseline at $4 \mathrm{~h}$ post-feeding. In 0900 h-fed cows, however, blood glucose remained constant without such a distinct peri-feeding rhythm. As such, postprandial insulin surges were higher for evening vs. morning feed ingestion. Thus, insulin action and glucose uptake relations to food provision and eating depend on when feed ingestion occurs.
Food presentation induces eating in individually-fed and grouphoused dairy cow models. Food provisions effects on eating activity may well persist even with multiple daily feeding. The literature suggests that dairy herbivores eat when fresh food is offered and that the amount eaten after a food delivery depends on the time of day. Anticipation of food presentation time may elongate eating time in cows. Thus, cows may anticipate an evening feeding better than morning feeding. Plasma insulin has been higher and glucose was lower at $2 \mathrm{~h}$ post-feeding in evening vs. morning fed cows. Higher insulin could weaken glucagon, thus reducing gluconeogenesis. It is, therefore, likely that higher blood insulin and lower glucose shortly post-feeding in evening, fed ruminants may delay the glucagon-driven satiety and increase postprandial eating rate.

In lactating herbivores fed once daily at $0900 \mathrm{~h}$, blood insulin exhibited distinct diurnal rhythms, with a peak at $1745 \mathrm{~h}$ and a nadir during 2300-0700 h. A similar blood insulin peak occurred at $1830 \mathrm{~h}$ and at $1800 \mathrm{~h}$. Thus, nervous signals rather than VFA alone appear, directly or via gut hormones to elicit a post-meal insulin response. Thus, diurnal and circadian rhythms of peripheral blood insulin are closely related to eating patterns. Circadian rhythms of peripheral blood insulin are more closely related to food content of non-structural carbohydrates, such as sugars and starch.

All the above leads the existing multispecies science to a solid suggestion that 'when to observe and ingest food' greatly matters in 'when to induce circadian insulin and glucose rhythms', 'when to beat obesity' and 'when to prevent and treat diabetes and related metabolic disorders'. Nutritional disorders can, therefore, be prevented and managed more effectively via modulating timing of food ingestion. This highlights the need for future large scale studies in different populations to develop global and local food regimens to ensure optimum public health and nutrition.

Acknowledgments: Thanks to the Ministry of Science, Research and Technology, and University of Zanjan for supporting the author's programs of optimizing science edification in the new millennium.

\section{References}

[1]. Dietary Reference Intakes (DRI). 2007. Recommended Intakes for Individuals, Food and Nutrition Board, Institute of Medicine, National Academies. National Academy of Sciences, Washington, D.C. USA.

[2]. Bassett JM. 1974. Early changes in plasma insulin and growth hormone levels after feeding in lambs and adult sheep. Aust. J. Biol. Sci. 27:157-166.

[3]. Furedi C, Kennedy AD, Nikkhah, A, Plaizier JC. 2006. Glucose tolerance and diurnal variation of circulating insulin in evening and morning fed lac- 
tating cows. Adv. Dairy Technol. 18:356.

[4]. Nikkhah A, Furedi CJ, Kennedy AD, Crow GH, Plaizier JC. 2008. Effects of feed delivery time on feed intake, rumen fermentation, blood metabolites and productivity of lactating cows. J. Dairy Sci. 91:1-12.

[5]. Nikkhah A. 2013. Chronophysiology of ruminant feeding behavior and metabolism: an evolutionary review. Biol. Rhythm Res. 44(2):197-218.

[6]. Nikkhah A. 2012. Time of Feeding an Evolutionary Science, Lap Lambert Publishing, GmbH \& Co. KG, Germany, ISBN 978-3-8473-3260-2.

[7]. Nikkhah A. 2011a. Science of eating time: A novel chronophysiological approach to optimize glucose-insulin dynamics and health. J. Diabetes Mellitus 2(1): $8-11$
[8]. Nikkhah A. 2011b. Ruminant chronophysiological management: an emerging bioscience. Open Access Anim. Physiol. 3:9-12.

[9]. Nikkhah A. 2011c. Eating timing an evolutionary manager of postmodern rumen physiology and health: a review. Open Access Anim. Physiol. 3:13-19.

[10]. Nikkhah A, Plaizier JC, Furedi CJ, Kennedy AD. 2006. Kennedy, Response in diurnal variation of circulating blood metabolites to nocturnal vs diurnal provision of fresh feed in lactating cows. J. Anim Sci. 84:111.

[11]. Trenkle A. 1970. Effects of short-chain fatty acids, feeding, fasting and type of diet on plasma insulin levels in sheep. J. Nutr. 100:323-1330. 